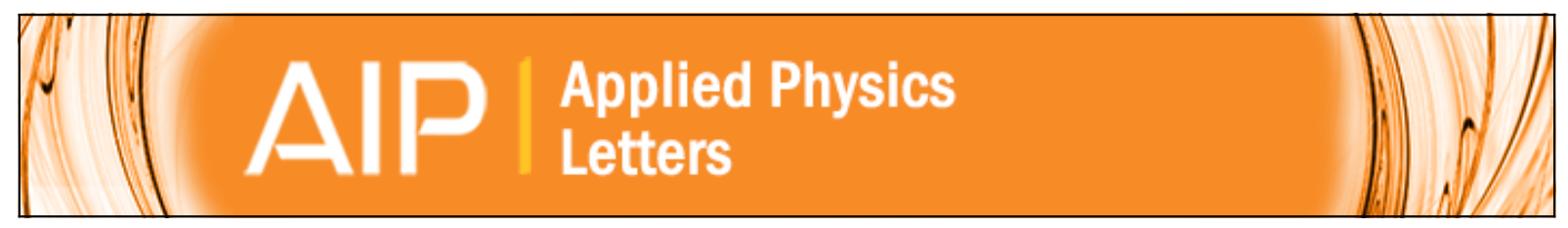

\title{
Creep-resistant composites of alumina and single-wall carbon nanotubes
}

Eugenio Zapata-Solvas, Rosalía Poyato, Diego Gómez-García, Arturo Domínguez-Rodríguez, Velimir

Radmilovic, and Nitin P. Padture

Citation: Applied Physics Letters 92, 111912 (2008); doi: 10.1063/1.2899945

View online: http://dx.doi.org/10.1063/1.2899945

View Table of Contents: http://scitation.aip.org/content/aip/journal/apl/92/11?ver=pdfcov

Published by the AIP Publishing

\section{Articles you may be interested in}

Fractal model for estimating fracture toughness of carbon nanotube reinforced aluminum oxide

J. Appl. Phys. 107, 123532 (2010); 10.1063/1.3445869

Strong and ductile nanostructured Cu-carbon nanotube composite

Appl. Phys. Lett. 95, 071907 (2009); 10.1063/1.3211921

Tribological and Strength Properties of Alumina/Multi-Walled Carbon Nanotube Composites

AIP Conf. Proc. 898, 154 (2007); 10.1063/1.2721269

Toughening and reinforcing alumina matrix composite with single-wall carbon nanotubes

Appl. Phys. Lett. 89, 121910 (2006); 10.1063/1.2336623

Electrical properties of nanoceramics reinforced with ropes of single-walled carbon nanotubes

Appl. Phys. Lett. 83, 1228 (2003); 10.1063/1.1600511

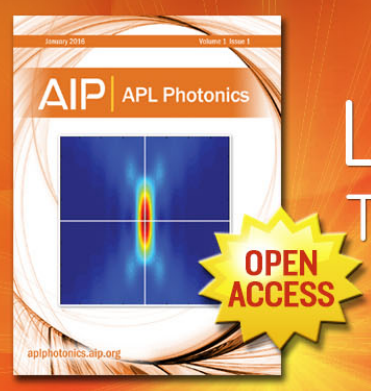

Launching in 2016!

The future of applied photonics research is here 


\title{
Creep-resistant composites of alumina and single-wall carbon nanotubes
}

\author{
Eugenio Zapata-Solvas, ${ }^{1}$ Rosalía Poyato, ${ }^{1}$ Diego Gómez-García, ${ }^{1}$ \\ Arturo Domínguez-Rodríguez, ${ }^{1, a)}$ Velimir Radmilovic, ${ }^{2}$ and Nitin P. Padture ${ }^{3, b)}$ \\ ${ }_{1}^{1}$ Departamento Física de la Materia Condensada, Universidad de Sevilla, 41080 Sevilla, Spain \\ ${ }^{2}$ National Center for Electron Microscopy, Lawrence Berkeley Laboratory, Berkeley, California 94720, USA \\ ${ }^{3}$ Department of Materials Science and Engineering, The Ohio State University, Columbus, \\ Ohio 43210, USA
}

(Received 17 December 2007; accepted 29 February 2008; published online 20 March 2008)

\begin{abstract}
Composites of alumina $\left(\mathrm{Al}_{2} \mathrm{O}_{3}\right)$ ceramic and single-wall carbon nanotubes (SWNTs) have been tested in uniaxial compression at 1300 and $1350{ }^{\circ} \mathrm{C}$ (Ar atmosphere), and they have been found to be about two orders of magnitude more creep-resistant compared to a pure alumina of about the same grain size $(0.5 \mu \mathrm{m})$. This is attributed to partial blocking of grain-boundary sliding by SWNTs in the composites. Since the grain boundaries in the ceramic/SWNTs composites are amenable to being engineered, this constitutes an attractive approach to the design of creep-resistant ceramic composites. (C) 2008 American Institute of Physics. [DOI: 10.1063/1.2899945]
\end{abstract}

Over the past decade or so there has been growing interest in composites of ceramics and carbon nanotubes (CNTs). ${ }^{1-17}$ This interest is primarily being driven by the idea that by combining CNTs with ceramics, one can impart some of the attractive mechanical properties of the CNTs (Ref. 18) to the resulting composites. There have been limited studies on single-wall CNTs (SWNTs) reinforced ceramics. ${ }^{6,9,13,15,19-25}$ An interesting aspect of alumina/ SWNTs composites is the unique grain-boundary structures they possess. In these composites, bundles of SWNTs have been found to segregate at the alumina grain boundaries. ${ }^{6,9,13}$ This grain-boundary structure is hierarchical in nature, and it comprises a three-dimensional network of two-dimensional mats made up of random one-dimensional SWNTs, which can be engineered. ${ }^{15}$ While grain boundaries have a profound influence on the high-temperature creep of polycrystalline materials, ${ }^{26}$ there have been no investigations on the influence of this unusual grain-boundary structure on the creep of alumina/SWNTs composites. Thus, the objective of this work is to determine if the unprecedented grain-boundary structures result in unusual creep behavior in alumina/SWNTs composites.

To that end, alumina/10 vol \% SWNTs composites were fabricated as part of an earlier study. ${ }^{13,15}$ The densities of the as-fabricated composites were $>97 \%$. These composites were cut into $4 \times 2 \times 2 \mathrm{~mm}^{3}$ rectangular parallelepipeds samples for creep tests. Uniaxial compression creep testing was performed using a method and equipment described elsewhere, ${ }^{27}$ at temperatures 1300 and $1350{ }^{\circ} \mathrm{C}$, and in the stress range of 47-256 $\mathrm{MPa}$. The temperatures used are high enough for diffusion processes to occur, but are sufficiently low to avoid grain growth. Argon gas atmosphere was used in order to avoid oxidation of the SWNTs.

Transmission electron microscopy (TEM) specimens from the as-prepared and the creep-deformed composites were prepared using conventional methods involving successive steps of grinding, polishing, dimpling, and ion-beam thinning (Fischione Instruments, Export, PA). The specimens were studied using a conventional $200 \mathrm{kV}$ TEM (CM200, Philips Electron Optics, Eindhoven, The Netherlands), a

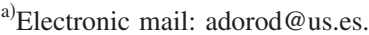

b)Electronic mail: padture.1@osu.edu.
}

high-resolution $300 \mathrm{kV}$ TEM (CM300), and a subangstrom resolution $300 \mathrm{kV}$ TEM (Titan, FEI, Hillsboro, OR).

Figure 1(a) shows a bright-field TEM image of the asfabricated alumina/SWNTs composite. The segregation of what appear to be SWNTs at the alumina grain boundaries is evident (see Fig. 2 for higher magnification images). It was noted in an earlier study that not all SWNTs survive the spark-plasma sintering treatment used to consolidate these composites. ${ }^{13}$ Therefore, in addition to SWNTs, other carbonaceous matter (amorphous carbon, graphite, multiwall CNTs) are likely to be present at the grain boundaries in these composites. Also evident in Fig. 1(a) is a lack of significant dislocation contrast within the alumina grains, and the average alumina grain size was determined to be $\sim 0.5 \mu \mathrm{m}$. ${ }^{13}$

Figure 1(b) shows a TEM micrograph of the alumina/ SWNTs composite deformed by $\sim 30 \%$ in compression at $1350{ }^{\circ} \mathrm{C}$. The presence of dislocation debris in the form of
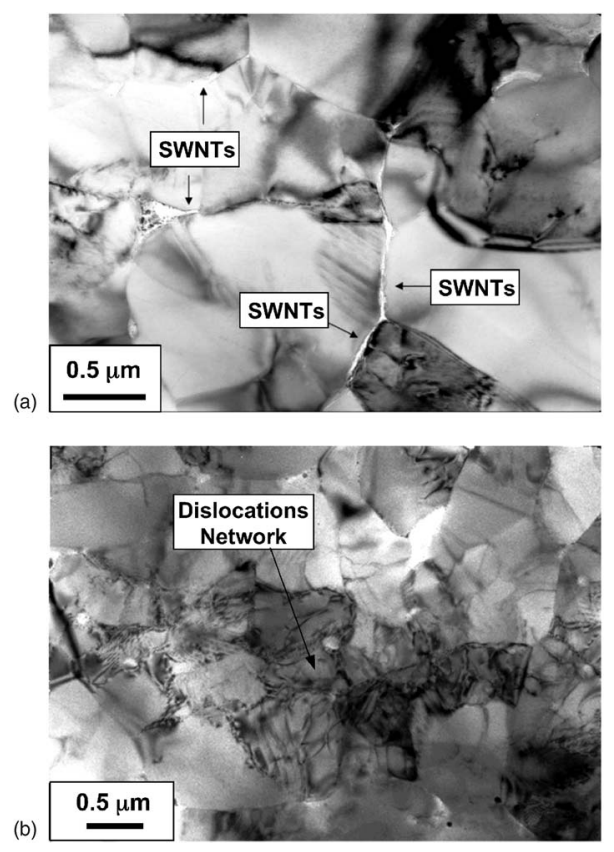

FIG. 1. Bright-field TEM micrographs of alumina/SWNTs composites: (a) before and (b) after creep deformation ( $\sim 30 \%$ strain). 


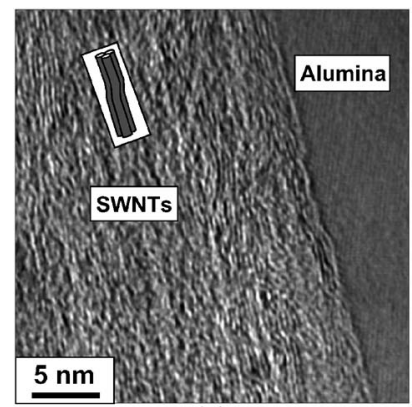

(a)

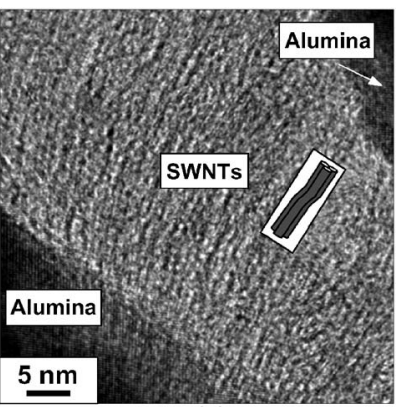

(b)
FIG. 2. HRTEM images of the as-prepared alumina/SWNTs composite showing what appear to be SWNTs bundles of different orientations at alumina grain boundaries.

subgrain cells within alumina grains is clearly evident in this micrograph. The grain size of the alumina was found to be unchanged after creep deformation.

Figures 2(a) and 2(b) are high-resolution TEM (HRTEM) images of the as-prepared alumina/SWNTs composite, showing what appear to be SWNTs bundles of different orientations at alumina grain boundaries. These images are similar to what were reported in earlier studies. ${ }^{13,15}$ Once again, the presence of some other carbonaceous matter at grain boundaries in these composites cannot be ruled out.

Figure 3(a) is a HRTEM image of the creep-deformed $(\sim 30 \%$ strain) alumina/SWNTs composite, clearly showing the presence of entangled SWNTs. The average diameter of these SWNTs appears to be around $0.33 \mathrm{~nm}$, which is much smaller than their typical size range between 0.5 and $2 \mathrm{~nm}^{28}$ Although the SWNTs smaller than $0.4 \mathrm{~nm}$ are energetically less favorable, it has been shown that they could be mechanically stable at temperature above $1000{ }^{\circ} \mathrm{C} .{ }^{29}$ Figure $3(\mathrm{~b})$ shows that, besides SWNTs, graphitic material is also present at alumina grain boundaries after deformation.

The composites, before and after creep testing, were characterized using a Raman confocal microspectrometer (LabRAM, Jobin Yvon, Edison, NJ), with $532 \mathrm{~nm}$ wavelength laser. Figure 4 shows Raman spectra in the $G$ band $\left(1550-1605 \mathrm{~cm}^{-1}\right), D$ band near $1350 \mathrm{~cm}^{-1}$, and the radial breathing mode (RBM) $\left(100-325 \mathrm{~cm}^{-1}\right)$ (Refs. 30 and 31) ranges, from the alumina/SWNTs composite before and after creep deformation. The Raman spectra remain unchanged, confirming the preservation of the carbon structure after creep deformation.

Figure 5 shows plots of steady-state creep rate $(\dot{\varepsilon})$ as a function of applied stress $(\sigma)$ for the alumina/SWNTs composite at two different temperatures: 1300 and $1350{ }^{\circ} \mathrm{C}$. For

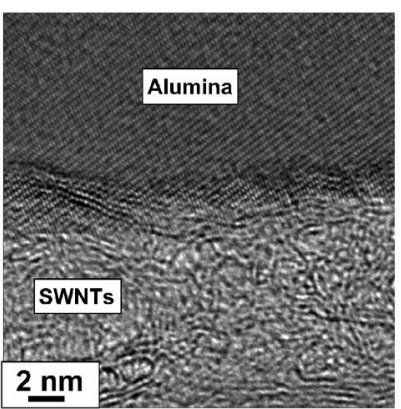

(a)

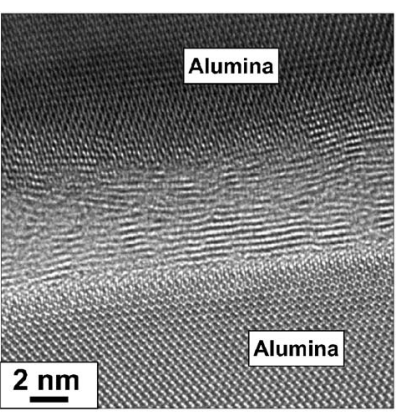

(b)
FIG. 3. HRTEM images of the creep-deformed alumina/SWNTs composite ( $\sim 30 \%$ strain) showing (a) SWNTs and (b) graphitic materia1, at alumina grain boundaries.

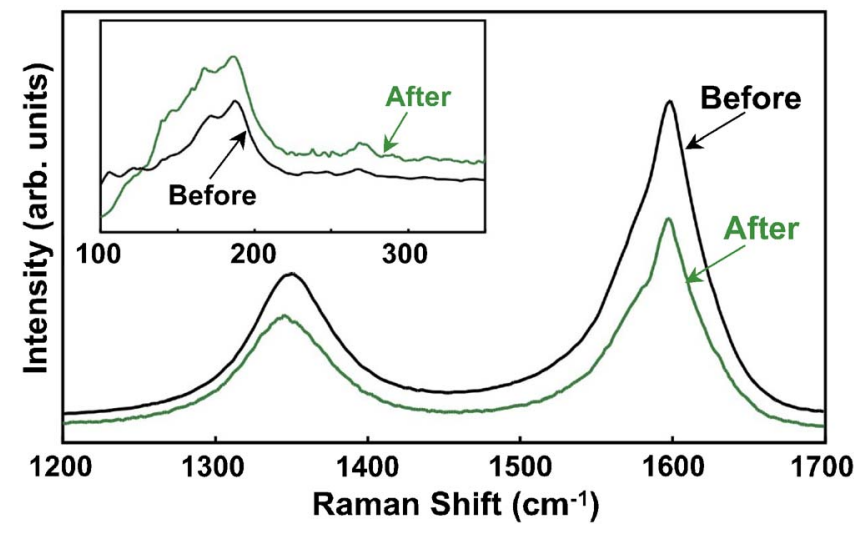

FIG. 4. (Color online) Raman spectra from alumina/SWNTs composites before and after creep deformation ( $\sim 30 \%$ strain) in the $G$-band and $D$-band ranges. Inset shows corresponding spectra in the RBM range.

comparison, uniaxial compression creep data from the literature $^{32}$ for high-purity alumina of about the same grain size $(0.5 \mu \mathrm{m})$ and density $(>98 \%)$, collected in the same temperature and applied-stress ranges, are included in Fig. 5.

The high-temperature steady-state creep of materials can be analyzed using the following equation: ${ }^{26}$

$$
\dot{\varepsilon}=A\left(\frac{\sigma}{G}\right)^{n} D_{0}^{\text {eff }} \exp \left[\frac{-Q}{k T}\right],
$$

where $A$ is a constant that includes the grain size dependence, $G$ is the shear modulus, $n$ is the stress exponent, $D_{0}^{\text {eff }}$ is the preexponential term of an effective diffusion coefficient, and $Q$ is the activation energy for the diffusion coefficient that controls the thermally activated transport of the atomic/ionic species. Analysis of the data in Fig. 5 using Eq. (1) shows that for the pure alumina $n \sim 1.7$ and $Q$ $\sim 460 \mathrm{~kJ} / \mathrm{mol}^{32}$ while for the alumina/SWNTs composite $n \sim 2.6$ and $Q \sim 660 \mathrm{~kJ} / \mathrm{mol}$. More importantly, the composite is found to be about two orders of magnitude more creep resistant as compared to the pure alumina.

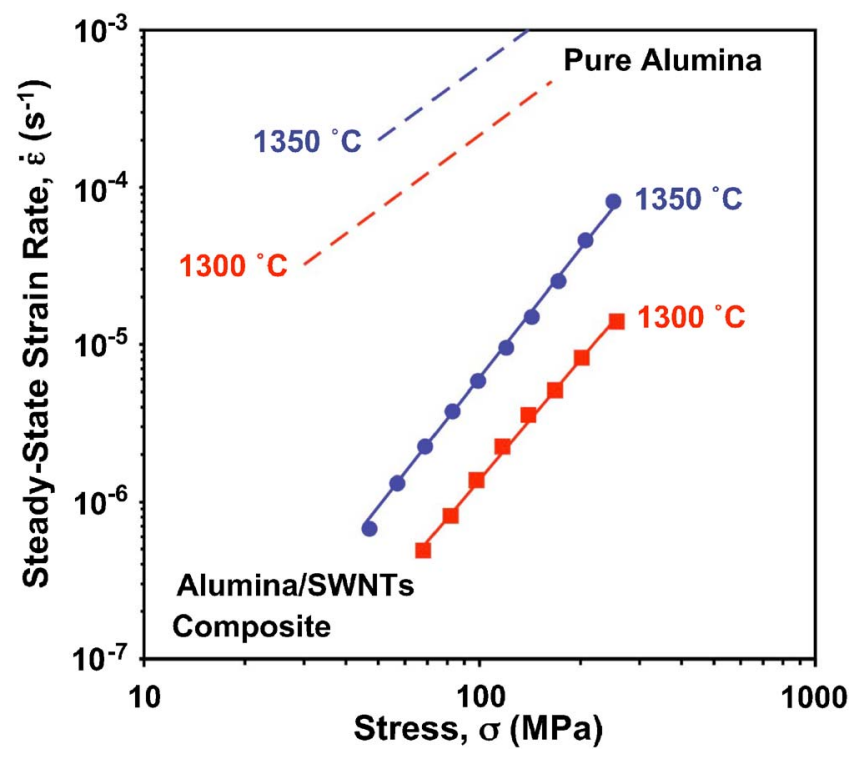

FIG. 5. (Color online) Plot of steady-state strain rate $(\dot{\varepsilon})$ vs applied compressive stress $(\sigma)$ data from the alumina/SWNTs composite at 1300 and $1350^{\circ} \mathrm{C}$. Solid lines are linear fits. For comparison, compression creep data at 1300 and $1350^{\circ} \mathrm{C}$ for pure alumina of $\sim 0.5 \mu \mathrm{m}$ grain size from the literature (Ref. 32) are included as dashed lines. 
First consider pure, fine-grained alumina, where hightemperature creep deformation generally occurs by coupled atomic/ionic diffusion and grain-boundary sliding. ${ }^{26}$ This mechanism results in a low stress exponent $n$ in the range of $1-2{ }^{33}$ The preferred diffusion path is grain boundaries, and the associated activation energy is in the range of $400-500 \mathrm{~kJ} / \mathrm{mol}{ }^{33,34}$ Furthermore, dislocation debris is generally not observed in creep-deformed fine-grained alumina at low and moderate applied-stress levels. Thus, a stress exponent of $n \sim 1.7$ and an activation energy of $Q$ $\sim 460 \mathrm{~kJ} / \mathrm{mol}$ for creep of pure alumina in Fig. 5 typify diffusional-transport creep coupled with grain-boundary sliding. ${ }^{32}$

Creep deformation can also occur by coupled dislocation slip (power law creep) and grain-boundary sliding, which results in higher stress exponents $(n \geqslant 2) \cdot{ }^{33,35,36} \mathrm{~A}$ stress exponent of $n \sim 2.6$ for the alumina/SWNTs composite points to power law creep in that material. The presence of a subgrain dislocation network in the creep-deformed alumina/ SWNTs composite [Fig. 1(b)] supports this hypothesis. ${ }^{35}$

Thus, the presence of SWNTs at grain boundaries in fine-grained alumina appears to be responsible for (i) a possible shift in the dominant creep mechanism from diffusional creep to power law creep and (ii) enhancement of creep resistance by about two orders of magnitude. The nature of grain-boundary sliding, which is associated with both diffusional creep and power law creep and which is influenced profoundly by the grain-boundary structure holds the key to understanding this effect.

In the case of pure, fine-grained alumina the grain boundaries are assumed to be "clean," where sliding is expected to occur unimpeded. ${ }^{35,36}$ Even if alumina grain boundaries have a thin film of glass, which is typically the case in aluminas of nominal purity, ${ }^{37}$ sliding is still expected to be unimpeded. This is due to the flow of the softened glassy phase, which is expected to be isotropic. ${ }^{35}$

In the case of the alumina/SWNTs composite, however, there is a tangled mat of random SWNT bundles at the grain boundaries. ${ }^{15}$ Sliding between SWNTs within the bundles [see, e.g., Fig. 2(a)] is likely to occur readily, as the secondary bonding between individual SWNTs is relatively weak. However, due to the random nature of the SWNTs it is highly likely that some SWNTs will be in orientations where they will subjected to tension [see e.g., Fig. 2(b), and HRTEM images in Ref. 15]. This is particularly true at triplegrain junctions. Since the anisotropy in the mechanical properties of SWNTs bundles is extreme, where SWNTs in uniaxial tension have a Young's modulus of $\sim 0.64 \mathrm{TPa}$ and a strength of $\sim 37 \mathrm{GPa},{ }^{18}$ it would take a small fraction of SWNTs that are oriented in the tension direction to impede significantly grain-boundary sliding in the composite. With the grain-boundary sliding partially blocked, higher stresses are needed to maintain a given steady-state strain rate, promoting dislocation slip.

In summary, we have shown that SWNTs at the alumina grain boundaries in alumina/SWNTs composites exert a significant influence on the creep properties of these composites. The two orders of magnitude improvement in the creep resistance of alumina/SWNTs composites over pure alumina of the same grain size could be highly beneficial in the design of creep-resistant ceramic composites. However, these composites would have to be protected from oxidation at high temperatures.
The authors thank Dr. H. Tanaka and Dr. T. Nishimura for performing spark-plasma sintering of the samples used in the study; Dr. A. L. Vasiliev and Dr. Z. Lee for performing some of the electron microscopy characterization; and Professor G. S. Daehn and Professor M. J. Mills for fruitful discussions. Funding for this work was provided by the Spanish CICYT (Research Project No. MAT2006-10249C02-02 and MAT2003-04199-C02-02), and by the Director, Office of Energy Research, Office of Basic Energy Sciences, Materials Sciences Division, U.S. Department of Energy under Contract No. DE-AC02-05CH11231.

${ }^{1}$ R. Z. Ma, J. Wu, B. Q. Wei, J. Liang, and D. H. Wu, J. Mater. Sci. 33, 5243 (1998).

${ }^{2}$ C. Laurent, A. Peigney, O. Dumortier, and A. Rousset, J. Eur. Ceram. Soc. 18, 2005 (1998).

${ }^{3}$ A. Peigney, C. H. Laurent, E. Flahaut, and A. Rousset, Ceram. Int. 26, 677 (2000).

${ }^{4}$ R. W. Siegel, S. K. Chang, B. J. Ash, J. Stone, P. M. Ajayan, R. W. Doremus, and L. S. Schadler, Scr. Mater. 44, 2061 (2001).

${ }^{5}$ J. Sun, L. Gao, and W. Li, Chem. Mater. 14, 5169 (2002).

${ }^{6}$ G.-D. Zhan, J. D. Kuntz, J. Wan, and A. K. Mukherjee, Nat. Mater. 2, 38 (2003).

${ }^{7}$ W. A. Curtin and B. W. Sheldon, Mater. Today 7, 44 (2004).

${ }^{8}$ L. An, S. Rajagopalan, C. Wang, H. Wang, Y. Fan, L. Zhang, D. Jiang, J. Kapat, L. Chow, B. Guo, J. Liang, and R. Vaidyanathan, Adv. Mater. (Weinheim, Ger.) 16, 2036 (2004).

${ }^{9}$ X. Wang, N. P. Padture, and H. Tanaka, Nat. Mater. 3, 539 (2004).

${ }^{10}$ Z. Xia, L. Riester, W. A. Curtin, H. Li, B. W. Sheldon, J. Liang, B. Chang, and J. M. Xu, Acta Mater. 52, 931 (2004).

${ }^{11}$ C. Balazsi, F. Weber, Z. Kover, Z. Konya, I. Kiricsi, L. P. Biro, and P. Arato, Key Eng. Mater. 290, 135 (2005).

${ }^{12}$ M. Daraktchiev, B. V. D. Moortele, R. Schaller, E. Couteau, and L. Forro, Adv. Mater. (Weinheim, Ger.) 17, 88 (2005).

${ }^{13}$ R. Poyato, A. L. Vasiliev, N. P. Padture, H. Tanaka, and T. Nishimura, Nat. Nanotechnol. 17, 1770 (2006).

${ }^{14}$ N. Grobert, Mater. Today 10, 28 (2007).

${ }^{15}$ A. L. Vasiliev, R. Poyato, and N. P. Padture, Scr. Mater. 56, 461 (2007).

${ }^{16}$ A. A. White, S. M. Best, and I. A. Kinloch, Int. J. Appl. Ceram. Technol. 4, 1 (2007).

${ }^{17}$ D. Jiang, K. Thomson, J. D. Kuntz, J. W. Ager, and A. K. Mukherjee, Scr. Mater. 56, 959 (2007).

${ }^{18}$ R. H. Baughman, A. A. Zakhidov, and W. A. deHeer, Science 297, 787 (2002).

${ }^{19}$ S. Rul, F. Lefevre-Schlick, E. Capria, C. Laurent, and A. Peigney, Acta Mater. 52, 1061 (2004).

${ }^{20}$ B. W. Sheldon and W. A. Curtin, Nat. Mater. 3, 505 (2004).

${ }^{21}$ Z. Burghard, D. Schon, J. Bill, and F. Aldinger, Int. J. Mater. Res. 97, 1667 (2006).

${ }^{22}$ J. P. Fan, D. M. Zhuang, D. Q. Zhao, G. Zhang, M. S. Wu, F. Wei, and Z. J. Fan, Appl. Phys. Lett. 89, 121910 (2006).

${ }^{23}$ T. Wang, Z. Iqbal, and S. Mitra, Carbon 44, 2804 (2006).

${ }^{24}$ G. Yamamoto, K. Yokomizo, M. Omori, Y. Sato, B. Jeyadevan, K. Motomiya, T. Hashida, T. Takahashi, A. Okubo, and T. Tohji, Nanotechnology 18, 145614 (2007).

${ }^{25}$ N. P. Padture and W. A. Curtin, Scr. Mater. (to be published).

${ }^{26}$ J. Poirier, Creep of Crystals (Cambridge University Press, Cambridge, UK, 1985).

${ }^{27}$ H. Gervais, B. Pellisier, and J. Castaing, Rev. Int. Hautes Temp. Refract. 15, 43 (1978).

${ }^{28}$ P. Kondratyuk and J. T. Yates, Acc. Chem. Res. 40, 995 (2007).

${ }^{29}$ L. M. Peng, Z. L. Zhang, Z. Q. Xue, Q. D. Wu, Z. N. Gu, and D. G. Pettifor, Phys. Rev. Lett. 85, 3249 (2000).

${ }^{30}$ M. S. Dresselhaus and P. C. Eklund, Adv. Phys. 49, 705 (2000).

${ }^{31}$ M. S. Dresselhaus, G. Dresselhaus, A. Joriob, A. G. S. Filho, and R. Saito, Carbon 40, 2043 (2002).

${ }^{32}$ L. A. Xue and I. W. Chen, J. Am. Ceram. Soc. 73, 3518 (1990).

${ }^{33}$ W. R. Cannon and T. G. Langdon, J. Mater. Sci. 23, 1 (1988).

${ }^{34}$ R. M. Cannon, W. H. Rhodes, and A. H. Heuer, J. Am. Ceram. Soc. 63, 46 (1980).

${ }^{35}$ A. H. Chokshi and T. G. Langdon, Mater. Sci. Technol. 7, 577 (1991).

${ }^{36}$ O. A. Ruano, J. Wadsworth, and O. D. Sherby, Acta Mater. 51, 3617 (2003).

D. R. Clarke, Annu. Rev. Mater. Sci. 17, 57 (1987). 